\title{
Central Nervous System Relapse of Whipple's Disease
}

\author{
Kiyoaki Uryu ${ }^{1}$, Takashi Sakai ${ }^{2}$, Tomonori Yamamoto ${ }^{4}$, Takahito Mae ${ }^{1}$, \\ Yoshie Iwasaki Willard ${ }^{3}$, Hiroji Sugita ${ }^{4}$, Koukichi Asano ${ }^{4}$, Kenichi Yamashita ${ }^{5}$, \\ Hiromasa Harada ${ }^{1}$ and Kou Fukuda ${ }^{6}$
}

\begin{abstract}
A 50-year-old man presented with a $12 \mathrm{~kg}$ weight loss in 8 months. Upper gastrointestinal endoscopy findings showed strong erosion and diffuse bleeding in the duodenum. Histopathological findings showed PAS staining-positive macrophages consistent with Whipple's disease. He was treated with trimethoprimsulfamethoxazole. His condition initially improved. However, during his 6-year course of treatment he developed a central nervous system relapse. Tropheryma whipplei DNA was detected by a polymerase chain reaction in his cerebrospinal fluid. This relapse was successfully treated with ceftriaxone sodium (CTRX). We considered that as initial therapy for Whipple's disease, it would be important to administer CTRX for at least a few months, due to its high translatability to CSF.
\end{abstract}

Key words: Whipple's disease, central nervous system disease, polymerase chain reaction, CTRX; ceftriaxone sodium, TMP-SMX; trimethoprim-sulfamethoxazole

(Intern Med 51: 2045-2050, 2012)

(DOI: 10.2169/internalmedicine.51.7304)

\section{Introduction}

Whipple's disease is a multisystem disease resulting from Tropheryma whipplei infection. Herein we report the progress of endoscopic and histopathological findings for eight years in one case diagnosed with Whipple's disease. This patient suffered a relapse in the central nervous system. And his clinical course was followed by polymerase chain reaction (PCR) using two kinds of primers and head-enhanced MRI.

\section{Case Report}

A 50-year-old Japanese man became aware of his general malaise and anorexia from around January 2000. A $12 \mathrm{~kg}$ weight loss was observed in the subsequent 8 months. Because the symptoms continued, in October 2000, he was admitted for tests. He had a history of cholecystectomy. Physi- cal examination findings on admission were as follows: height; $170 \mathrm{~cm}$, body weight; $50 \mathrm{~kg}$, body mass index; 17.3 $\mathrm{kg} / \mathrm{m}^{2}$, body temperature; $37.6^{\circ} \mathrm{C}$, blood pressure; $105 / 70$ $\mathrm{mmHg}$, and pulse; 75 beats per minute. His consciousness was alert and neurological findings were normal. His auscultation, respiratory and cardiac sounds were normal, and no abdominal sounds were noted. His laboratory findings on admission are shown in Table 1.

He was treated with intravenous hyperalimentation and antibiotics (ceftriaxone sodium: CTRX 2 g/day, and isepamicin: ISP $200 \mathrm{mg} /$ day). His fever went down, and his general condition improved gradually. He was discharged in December 2000. During outpatient observation, his symptoms of anorexia and emaciation grew worse. Due to the results of his high Scl 70 score, immune complex (anti C3d antibody) and ferritin, he was suspected of collagen disease. He was started on oral prednisolone: PSL (15 mg/day), in late December 2000. His appetite improved and his weight increased. PSL was tapered to $5 \mathrm{mg} /$ day in mid-July 2001. In

\footnotetext{
${ }^{1}$ Department of Respiratory Medicine, Yao Tokushukai General Hospital, Japan, ${ }^{2}$ Department of General Internal Medicine, Obihiro Daiichi Hospital, Japan, ${ }^{3}$ Department of Cytology, Yao Tokushukai General Hospital, Japan, ${ }^{4}$ Department of Gastroenterology, Yao Tokushukai General Hospital, Japan, ${ }^{5}$ Department of Pathology, Yao Tokushukai General Hospital, Japan and ${ }^{6}$ Department of Cardiovascular Medicine, Yao Tokushukai General Hospital, Japan

Received for publication January 15, 2012; Accepted for publication April 9, 2012

Correspondence to Dr. Kiyoaki Uryu, kiyoaki2377@yahoo.co.jp
} 
Table 1. Laboratory Findings on Admission

\begin{tabular}{|c|c|c|c|}
\hline \multicolumn{2}{|l|}{ Hematology } & \multicolumn{2}{|c|}{ Biochemistry } \\
\hline WBC & $5,200 / \mu \mathrm{L}$ & $\mathrm{TP}$ & $5.2 \mathrm{~g} / \mathrm{dL}$ \\
\hline neu & $71.6 \%$ & Alb & $2.4 \mathrm{~g} / \mathrm{dL}$ \\
\hline lym & $24.2 \%$ & $\mathrm{ChE}$ & $62 \mathrm{IU} / \mathrm{L}$ \\
\hline mono & $2.5 \%$ & T-Bil & $0.4 \mathrm{mg} / \mathrm{dL}$ \\
\hline baso & $0.2 \%$ & $\gamma$-GTP & $11 \mathrm{IU} / \mathrm{L}$ \\
\hline eos & $1.5 \%$ & AST & $33 \mathrm{IU} / \mathrm{L}$ \\
\hline $\mathrm{RBC}$ & $303 \times 10^{4} / \mu \mathrm{L}$ & ALT & $14 \mathrm{IU} / \mathrm{L}$ \\
\hline $\mathrm{Hb}$ & $8.1 \mathrm{~g} / \mathrm{dL}$ & T Chol & $67 \mathrm{mg} / \mathrm{dL}$ \\
\hline $\mathrm{Ht}$ & $24.6 \%$ & TG & $53 \mathrm{mg} / \mathrm{dL}$ \\
\hline PLT & $18.4 \times 10^{4} / \mu \mathrm{L}$ & $\mathrm{LDH}$ & $351 \mathrm{IU} / \mathrm{L}$ \\
\hline \multicolumn{2}{|l|}{ Serology } & FBS & $81 \mathrm{mg} / \mathrm{dL}$ \\
\hline ANA & $<40$ times & BUN & $19.3 \mathrm{mg} / \mathrm{dL}$ \\
\hline Anti-ds DNA antibody & $1.9 \mathrm{IU} / \mathrm{mL}$ & Cre & $0.7 \mathrm{mg} / \mathrm{dL}$ \\
\hline Anti-ss DNA antibody & $9.9 \mathrm{AU} / \mathrm{mL}$ & $\mathrm{Na}$ & $130 \mathrm{mEq} / \mathrm{L}$ \\
\hline Anti-Jo 1 antibody & $<1$ times & $\mathrm{K}$ & $4.4 \mathrm{mEq} / \mathrm{L}$ \\
\hline Anti-RNP antibody & $<5.0$ Index & $\mathrm{Cl}$ & $102 \mathrm{mEq} / \mathrm{L}$ \\
\hline Anti-Sm antibody & $<5.0$ Index & CRP & $3.7 \mathrm{mg} / \mathrm{dL}$ \\
\hline Anti-Scl 70 antibody & 11.6 Index & & \\
\hline PR3-ANCA & $<3.1 \mathrm{EU}$ & \multicolumn{2}{|l|}{ Hormones } \\
\hline MPO-ANCA & $<3.1 \mathrm{EU}$ & TSH & $2.26 \mu \mathrm{IU} / \mathrm{mL}$ \\
\hline Anti-centromere antibody & $<5.0$ index & Free $\mathrm{T}_{3}$ & $3.7 \mathrm{pg} / \mathrm{mL}$ \\
\hline $\mathrm{CH}_{50}$ & $41.4 \mathrm{U} / \mathrm{mL}$ & Free $\mathrm{T}_{4}$ & $1.1 \mathrm{ng} / \mathrm{dL}$ \\
\hline C 3 & $122 \mathrm{mg} / \mathrm{dL}$ & ACTH & $54.8 \mathrm{pg} / \mathrm{mL}$ \\
\hline $\mathrm{C} 4$ & $27 \mathrm{mg} / \mathrm{dL}$ & Cortisol & $18.7 \mu \mathrm{g} / \mathrm{dL}$ \\
\hline Ferritin & $1,180 \mathrm{ng} / \mathrm{mL}$ & & \\
\hline IC (Anti-C3d antibody) & $16.4 \mu \mathrm{g} / \mathrm{mL}$ & & \\
\hline
\end{tabular}

ANA: anti-nuclear antibody, PR3-ANCA: proteinase 3 anti neutrophil cytoplasmic antibody, MPO-ANCA:

myeloperoxidase anti neutrophil cytoplasmic antibody, $\mathrm{CH}_{50}$ : total hemolytic complement, $\mathrm{C} 3$ : third components of complement, C4: fourth components of complement, IC: immune complex, ACTH: adrenocorticotropic hormone,

TSH: thyroid stimulating hormone

April 2002, he became aware of the malaise. Diarrhea and tarry stool were observed. He was hospitalized and upper gastrointestinal bleeding was suspected. Upper gastrointestinal endoscopy findings showed strong erosion and diffuse bleeding in the distal duodenum from the descending limb. Histopathological findings showed PAS staining-positive macrophages which are consistent with Whipple's disease (Fig. 1). And Fig. 2 shows electron microscopic findings which detect the distinctive trilaminar cell wall of $T$. whipplei. He was treated with $120 \mathrm{mU} /$ day of penicillin G (PCG) from mid-June 2002. Systemic arthritis appeared after PCG medication. He refused PCG continuous medication, so we switched to oral administration of trimethoprim-sulfamethoxazole (TMP-SMX 4 g/day). He responded with rapid clinical remission. He has been free from digestive symptoms, such as diarrhea. He has been free from symptoms and has gained weight for six years due to the continuous administration of TMP-SMX.

From March 2008, his wife noticed that his forgetfulness had become severe. There was no change in his character. Transient difficulty in walking appeared and forgetfulness worsened in April 2008. Dilatation of the lateral ventricle and third ventricle was observed in his head MRI. The anterior commissure had been enhanced by meglumine gadopentetate $(\mathrm{Gd})$. However, there was no obstruction origin seen on the MRI (Fig. 4). He was hospitalized for medical treatment and examination due to suspicion of hydrocephalus. He was awake and alert, oriented to place and person, and able to follow commands. His cranial nerve examination was intact. His motor power, sensation, and deep tendon reflexes were normal. He demonstrated broad-base gait and magnet gait. We performed neuropsychological tests. The following are the results of the tests. Mini-Mental State Examination (MMSE) 30/30 points, Revised Hasegawa Dementia Scale (HDS-R) 26/30 points (disorientation of time and delayed recall of words), and Wechsler Memory ScaleRevised (WMS-R): Auditory Memory 83, Visual Memory 84, Visual Working Memory 81, Immediate Memory 113 and Delayed Memory 81. We performed a spinal tap which resulted in gait and encoding improvement after cerebrospinal fluid (CSF) removal. His CSF findings were negative color, pressure; $11 \mathrm{cmH}_{2} \mathrm{O}$, cell counts; $62 / \mu \mathrm{L}$ (monocyte 


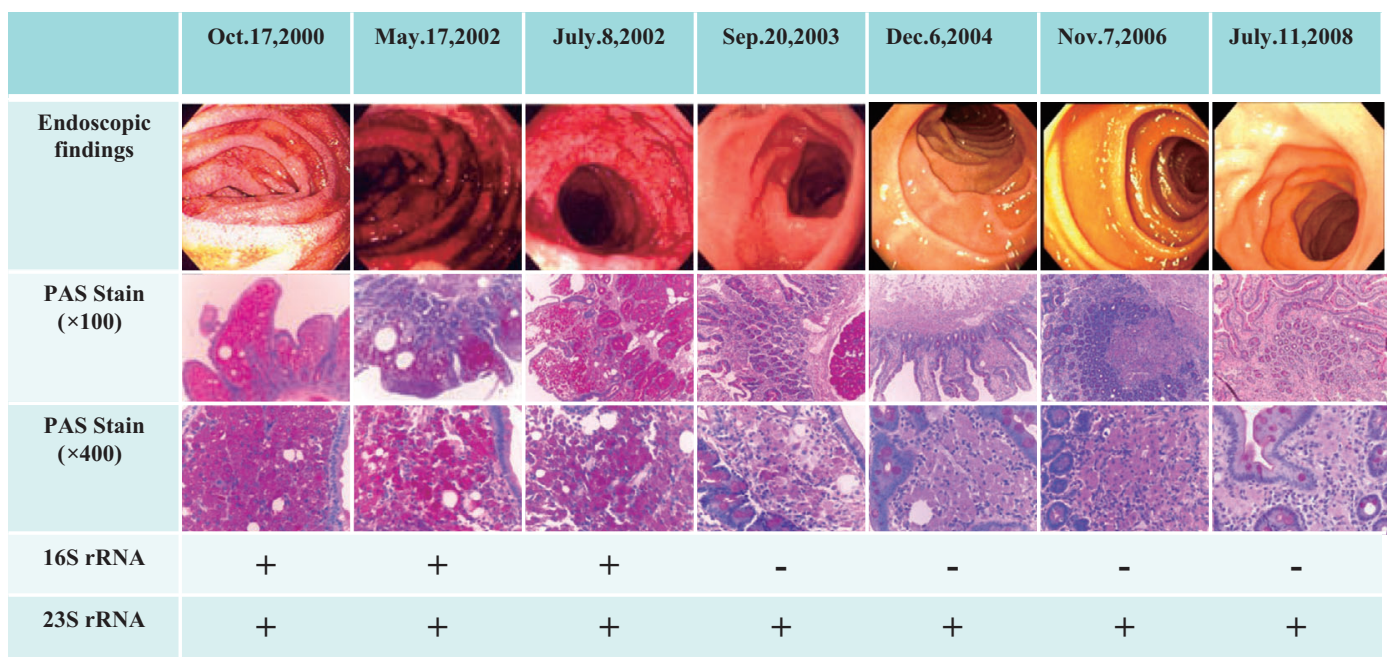

Figure 1. First panel show endoscopic findings, 2nd. panel show histopathological findings with PAS stain $(\times 100)$, and 3rd.panel $(\times 400)$. PAS staining of duodenal biopsy specimens show magentastained inclusions within macrophages of the lamina propria. 4th.panel show the results of PCR using 16S rRNA (W3AF-W4AR), 5th. panel show the results of PCR using 23S rRNA (HGC23InsFTW23InsR1 and TW23InsF-TW23InsR2). The results of PCR using 16S rRNA were negative after the improvement of symptoms.

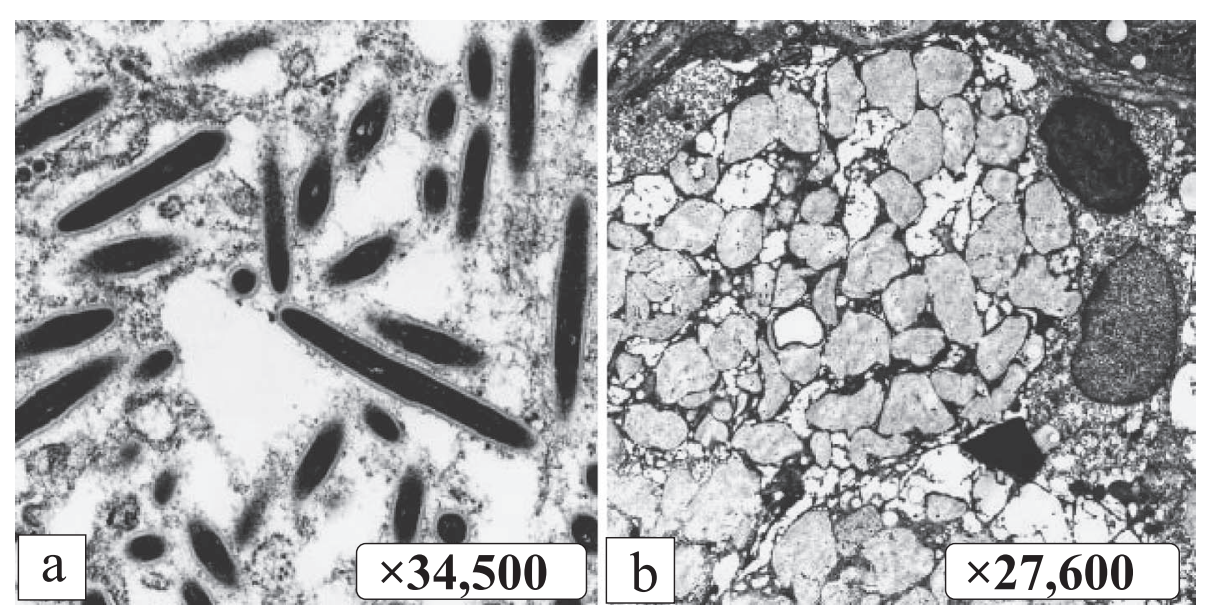

Figure 2. a: show electron microscopic findings which detect the distinctive trilaminar cell wall of T. whipplei. b: show fine fibrous structure, in foamy macrophages, which persisted after the treatment while bacteria disappeared.

$100 \%$ ), TP; $107.6 \mathrm{~g} / \mathrm{dL}$, Glu; $53 \mathrm{mg} / \mathrm{dL}$ and $\mathrm{Cl} ; 128 \mathrm{mEq} / \mathrm{L}$. Cytological findings showed PAS-positive macrophages in CSF (Fig. 3). PCR was performed to identify Whipple's disease according to a method using two specific primers; one of W3AF-W4AR (1) and the other of HGC23InsF-TW23 InsR1, TW23InsF-TW23InsR2 (2). Both PCR results were positive, so we diagnosed him with a central nervous system relapse of Whipple's disease. We performed spinal drainage for 7 days and treated him with antibiotics (CTRX $2 \mathrm{~g}$ IV twice a day for 4 weeks). His treatment was switched to oral administration of TMP-SMX $4 \mathrm{~g} /$ day after his central nervous symptoms improved. Currently, relapse of his symptoms are not observed and the results of HDS-R has improved.
His endoscopic findings, histopathological findings, and the results of PCR from the onset up to the present can be seen in Fig. 1. His enhanced MRI findings and the results of PCR from the central nervous system relapse of Whipple's disease up to the present can be seen in Fig. 4. Moreover, we performed a perfusion-weighted image (PW). The cerebral blood flow (CBF) was satisfactory over the course of treatment.

\section{Discussion}

Whipple's disease is a systemic inflammatory disease due to Tropheryma whipplei first reported in 1907 by George H. Whipple (3). Whipple's disease is a rare systemic infectious 


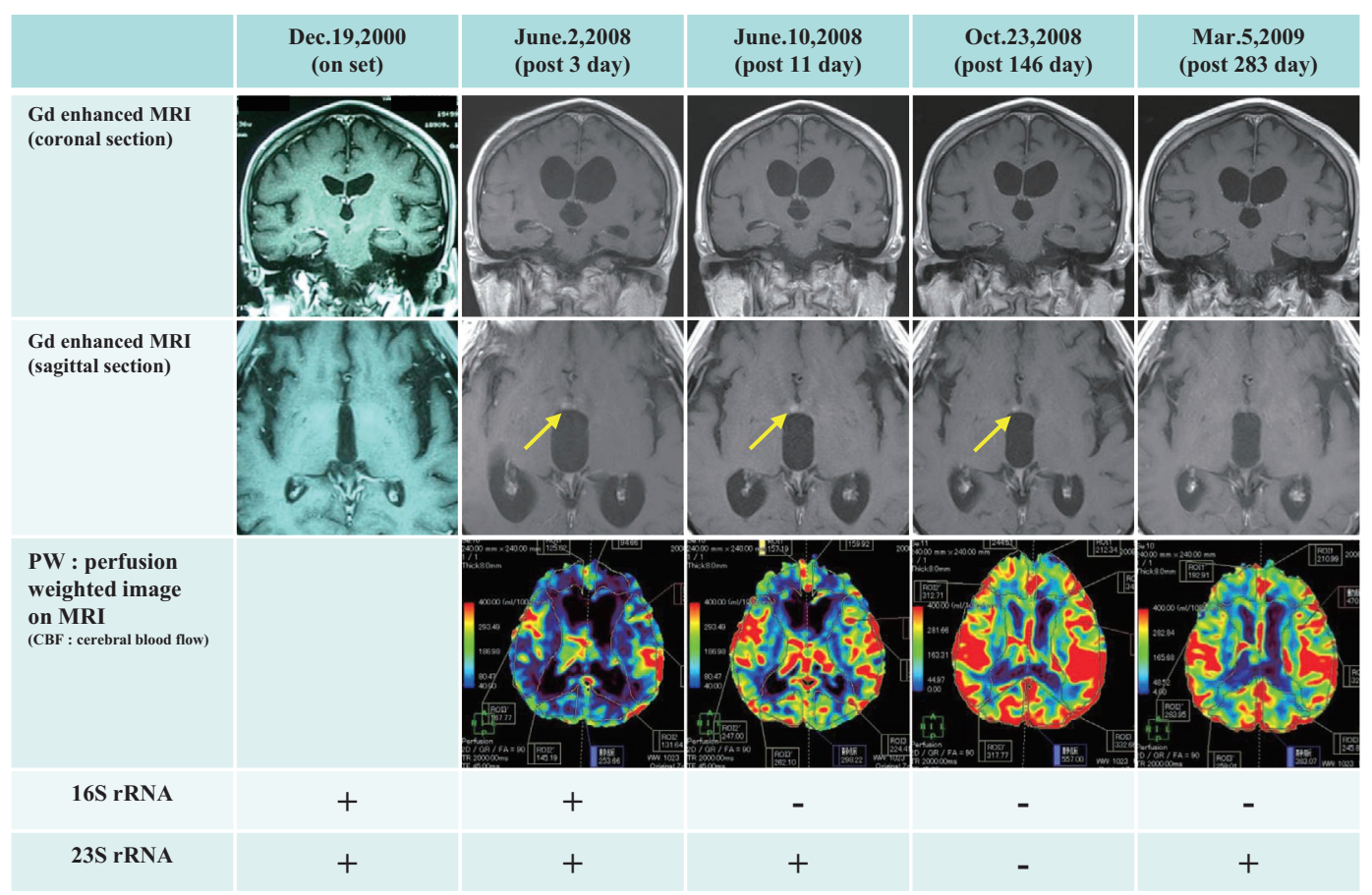

Figure 4. First panel show that the dilatation lateral ventricle and third ventricle tend to improvement in MRI. 2nd. panel show the front wall of the third ventricle, which was enhanced by Gd (arrow). Contrast effect disappeared gradually with symptomatic improvement. 3rd.panel show perfusion weighted image (PW). The cerebral blood flow (CBF) was well over the course of treatment. 4th.panel show the PCR results in CSF using 16S rRNA primer. 5th. panel show the results of PCR using 23S rRNA primer. The results of PCR using 16S rRNA were negative after the improvement of symptoms.

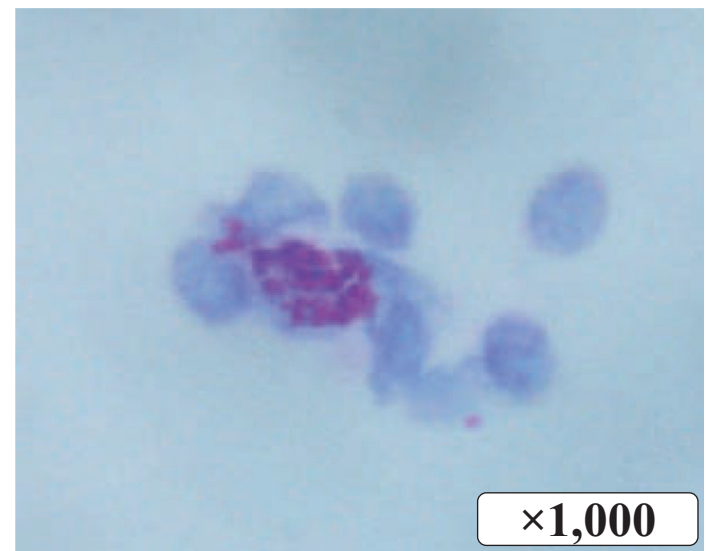

Figure 3. Microscopic findings show PAS-positive macrophages in CSF.

disorder with an estimated incidence of 0.4 per 1,000,000 a year (4). Whipple's disease is characterized by two stagesa prodromal stage and a much later steady-state stage. The prodromal stage is marked by protean symptoms, along with chronic nonspecific findings, mainly arthralgia and arthritis. The steady-state stage is typified by weight loss, diarrhea, or both, and occasionally there are other manifestations, since many organs can be involved. The average time between the prodromal and the steady-state stages is 6 years $(5,6)$. In the present case the gastrointestinal symptoms, such as weight loss and diarrhea which appeared in 2000, were equivalent to those of the steady-state stage.

Roughly $15 \%$ of patients with Whipple's disease do not have the classic signs and symptoms of the disease. Accordingly, the diagnosis should be considered in many different clinical circumstances $(7,8)$. Because to date present, Whipple's disease has been infrequently reported in Japan (9), the present case was very difficult to diagnose. If a patient has received immunosuppressive therapy, such as treatment with corticosteroids or tumor necrosis factor antagonists, a more rapid clinical progression may occur $(10,11)$. The current patient was treated with PSL, because we considered the possibility of collagen disease based on his symptoms. The rapid appearance of clinical symptoms can be considered due to the administration of PSL. Without treatment, Whipple's disease is ultimately fatal. Even with a specific antibiotic regimen, clinical relapse occurs in 2 to $33 \%$ of cases after an average of 5 years. Relapse is usually characterized by neurologic involvement (12). For the present case, we were able to start the TMP-SMX, because we made a definitive diagnosis of Whipple's disease and thus we were able to provide effective treatment for the steady-state stage. However, this patient had a central nervous system manifestation of Whipple's disease despite administration of TMPSMX over a long period of nearly six years. Neurologic involvement has been reported in 6 to $63 \%$ of patients with classic Whipple's disease $(10,13,14)$. Cognitive changes are common, affecting $71 \%$ of patients with neurologic 
signs, and may even extend to dementia. Central nervous system (CNS) manifestation is observed simultaneously with the cognitive changes, such as the forgetfulness and gait disturbance in this case. The typical findings of CT cisternography in normal pressure hydrocephalus (NPH) are intraventricular reflux and stagnation on the brain surface of the contrast media, but in the present case there was no finding of intraventricular reflux. A study reported improvement of symptoms in $69 \%$ of patients showing ventricular stasis at 48 hours after injection, and in 58\% of patients showing no ascent to the brain surface (15). (1)In the present case after a spinal tap, the patient's gait disturbance was remarkably improved. (2)Although we performed spinal drainage for 7 days only and treated him with CTRX, his neurological symptoms were improved without a ventriculo-peritoneal shunt. (3)His anterior commissure enhanced by Gd was lost over the course of treatment and there were no symptom such as agnosia of the right or left. Based on these three points of the present case, we concluded that neurological findings of the present case were derived from secondary NPH due to meningitis of Whipple's disease.

Massive infiltration of infected tissues by macrophages on microscopy typifies Whipple's disease (16). Several studies have demonstrated defective macrophage function in patients with the disease. Although macrophages from affected patients phagocytose bacteria normally, they appear to be unable to degrade bacterial antigens efficiently (13). In the present case the PAS-positive inclusions within cells are considered to be macrophages phagocytosis of bacteria from electron microscope findings. After the onset, upper gastrointestinal endoscopy is performed once a year, the histological findings of duodenal mucosal biopsies and the results of PCR are shown in Fig. 1. Despite the fact that administration of TMP-SMX has been continued, the PAS-positive inclusions still remain under duodenal mucosa. These findings suggest that the macrophage function of this disease is abnormal. The PAS-positive cells in CSF were considered an effective inspection and diagnosis of Whipple's disease in central nervous system manifestation of relapse.

PCR can be used to detect $T$. whipplei in samples from a variety of tissue types and body fluids. Initially, PCR assays targeting the $16 \mathrm{~S}$ rRNA gene and 16S-23S intergenic regions of the T. whipplei gene were used. The strategy of Florence et al. for diagnosing Whipple's disease uses the results of PAS staining and PCR in parallel (6). Compared to microscopic analysis, PCR assays targeting the 16S rRNA gene seem to be more sensitive. Several cases of Whipple's disease with negative histopathological findings but positive PCR results have been reported. Such PCR results should be confirmed by additional tests. Using the primer of Dominant III 23S rRNA gene has been reported to be effective in addition to the primer of 16S rRNA gene (2). In the past, we examined the mucosal tissue and the CSF of the present case by PCR using two primers (16S rRNA gene and Dominant III of 23S rRNA gene). The 16S rRNA gene PCR results of the mucosal tissue became negative together with improvements in disease activity. On the other hand, dominant III 23S rRNA gene PCR results remained positive and continued until relapse in the central nervous system manifestation. The results of this case, when the disease is in remission, show that $16 \mathrm{~S}$ rRNA gene PCR results are negative changes. Using the dominant III 23S rRNA gene PCR, we can check the remaining T. whipplei and suggest that the diagnosis can be more reliable.

The following is the recommended treatment. Parenteral ceftriaxone ( 2 g IV once daily) or penicillin (2MU IV every 4 hours) for two weeks followed by TMP-SMX (one double-strength tablet twice a day) for one year (17). For patients who relapse: PCG (4MU IV every 4 hours) or CTRX (2 g IV twice daily) for four weeks followed by oral doxycycline (100 mg twice daily) in combination with hydroxychloroquine (200 mg PO thrice daily) or TMP-SMX (one double-strength tablet twice a day) for one year (25). In the present case, as initial therapy, when it is difficult to continue intravenous injection of PCG, we had to change to oral TMP-SMX, because the patient refused administration of the PCG. Oral TMP-SMX has shown rapid improvement of clinical symptoms, but relapsed in central nervous system manifestation. In about four weeks of continuing CTRX administration after relapse, neurological symptoms and PCR results of CSF showed improvement. Although a tendency toward improvement can be seen, the dilatation of the lateral ventricle has remained on the MRI. We must continue strict observation in the present case, because it has been known that the recurrence of Whipple's disease with CNS is higher. If a recurrence can be seen, we suggest CTRX for four weeks followed by oral doxycycline in combination with TMP-SMX for one year, because we cannot administer hydroxychloroquine in Japan. We considered that as initial therapy for Whipple's disease, it is important to administer antibiotics (CTRX or PCG) for at least a few months, due to its high translatability to CSF.

\section{The authors state that they have no Conflict of Interest (COI).}

\section{Acknowledgement}

We thank Dr. Chikugo (Department of Pathology, Kinki University Faculty of Medicine) for his excellent microscopic examination.

\section{References}

1. Ramzan NN, Loftus E Jr, Burgart LJ, et al. Diagnosis and monitoring of Whipple disease by polymerase chain reaction. Ann Intern Med 126: 520-527, 1997.

2. Hinrikson HP, Dutly F, Altwegg M. Evaluation of specific nested PCR targeting domain III of the 23S rRNA gene of "Tropheryma whippleii" and proposal of a classification system for its molecular variants. J Clin Microbiol 38: 595-599, 2000.

3. Whipple GH. A hitherto undescribed disease characterized anatomically by deposits of fat and fatty acids in the intestinal and mesenteric lymphatic tissues. Bull Johns Hopkins Hosp 18: 382391, 1907.

4. Marth T, Raoult D. Whipple's disease. Lancet 361: 239-246, 
2003.

5. Puechal $X$. Whipple disease and arthritis. Curr Opin Rheumatol 13: 74-79, 2001.

6. Florence F, Xavier P, Didier R. Whipple's disease. N Engl J Med 356: 55-66, 2007.

7. Misbah SA, Mapstone NP. Whipple's disease revisited. J Clin Pathol 53: 750-755, 2000.

8. Durand DV, Lecomte C, Cathebras P, Rousset H, Godeau P. Whipple disease: clinical review of 52 cases. Medicine (Baltimore) 76: 170-184, 1997.

9. Yogi T, Hokama A, Kinjo F, et al. Whipple's disease: the first Japanese case diagnosed by electron microscopy and polymerase chain reaction. Intern Med 43: 566-570, 2004.

10. Gerard A, Sarrot-Reynauld F, Liozon E, et al. Neurologic presentation of Whipple disease: report of 12 cases and review of the literature. Medicine (Baltimore) 81: 443-457, 2002.

11. Mahnel R, Kalt A, Ring S, Stallmach A, Strober W, Marth T. Immunosuppressive therapy in Whipple's disease patients is associated with the appearance of gastrointestinal manifestations. Am J Gastroenterol 100: 1167-1173, 2005.
12. Keinath RD, Merrell DE, Vlietstra R, Dobbins WO III. Antibiotic treatment and relapse in Whipple's disease: long term follow-up of 88 patients. Gastroenterology 88: 1867-1873, 1985.

13. Dobbins WO III. Whipple's Disease. Thomas, Springfield, IL 1987.

14. Louis ED, Lynch $T$, Kaufmann $P$, Fahn S, Odel J. Diagnostic guidelines in central nervous system Whipple's disease. Ann Neurol 40: 561-568, 1996.

15. Benzel EC, Palletier AL, Pamela GL. Communicating hydrocephalus in adults; prediction of outcome after ventricular shunting procedures. Neurosurgery 26: 655-660, 1990.

16. Lepidi H, Fenollar F, Gerolami R, et al. Whipple's disease: immunospecific and quantitative immunohistochemical study of intestinal biopsy specimens. Hum Pathol 34: 589-596, 2003.

17. Feurle GE. Whipple's disease. Orphanet Encyclopedia 2004; http://www.orpha.net/data/patho/GB/uk-WhipplesDisease.pdf

18. Masselot F, Boulos A, Maurin M, et al. Molecular evaluation of antibiotic susceptibility: Tropheryma whipplei paradigm. Antimicrob Agents Chemother 47: 1658, 2003.

(C) 2012 The Japanese Society of Internal Medicine http://www.naika.or.jp/imindex.html 